\title{
Careers in Core Facility Management
}

\author{
Claire M. Brown \\ McGill University Life Sciences Complex, Advanced Biolmaging Facility (ABIF), Montreal, \\ Quebec H3G OB1, Canada \\ Correspondence: claire.brown@mcgill.ca
}

The need for centralized shared core facilities and highly qualified core facility staff is becoming increasingly important in universities, research institutes, and commercial laboratories. With the continued advancement and sophistication of scientific equipment typically comes a larger price tag than can be handled by individual research laboratories. Moreover, the ever-increasing need for researchers to think and act in cross-disciplinary environments, coupled with the increasing sophistication of both the instrumentation and associated technologies, prevents most researchers from becoming "experts" in all areas.

At all levels, core facility positions involve a love of technology, working with people, working on many diverse scientific questions, and days full of multitasking. Entry-level positions include basic and advanced technicians that require a BSc or MSc degree and some experience in the field. Midlevel management positions require experience in the field and an MSc or PhD degree. Management experience is a plus but not always required. Scientific directorship positions require a $\mathrm{PhD}$ and a keen interest in the technologies that are typically applied in the director's research program. Associate deans of core resources are often former core managers or scientific directors with a vision for the core and who are strong administrators.

A career as a core facility staff member can be very rewarding. Successful managers and directors must be able to multitask, reassess priorities, and be adept at using logical reasoning to identify and solve issues as they arise. These positions will continue to be available over the long term with the increasing complexity and continued fast pace of technology development.

$\mathrm{D}$ uring the last decade, technology has advanced by leaps and bounds. Researchers are also moving into more cross-disciplinary research programs that involve complementary but highly diverse technologies, making it nearly impossible for principal investigators to keep up with all of the intricate details of the rapidly changing technologies used in their research programs. As technologies become more sophisticated, the cost of implementing them in- creases. It is rare, therefore, that individual research laboratory budgets can allow a given laboratory to acquire, run, and maintain advanced technological platforms. Most importantly, to implement these technologies to their fullest potential, highly trained $\mathrm{PhD}$-level scientists must be hired, engaged in the research programs, and retained over the long term.

To stay competitive, recruit top scientists, and maximize return on investment, many in-

Editors: Kaaren Janssen and Richard Sever

Additional Perspectives on Career Options for Biomedical Scientists available at www.cshperspectives.org

Copyright (C) 2018 Cold Spring Harbor Laboratory Press; all rights reserved; doi: a032805

Cite this article as Cold Spring Harb Perspect Biol 2018;10:a032805 
stitutions are moving toward centralized shared facilities in many areas (http://stm.sciencemag .org/content/3/95/95cm21; https://www.ncbi .nlm.nih.gov/pmc/articles/PMC3221450/). In some countries, as in the United States, the push for centralized resources comes from the granting agencies themselves through programs such as the National Institutes of Health (NIH) shared instrumentation grants. These grants require researchers to demonstrate need, show that the technologies will support numerous research programs, and show that the institution has the infrastructure and support, including highly qualified personnel, to support state-of-the-art equipment over the long term. This equipment is then required to be placed in accessible centralized facilities. In a relatively unique initiative, the state of Victoria in Australia has developed a state-funded centralized network (Victorian Platform Technologies Network, http://www .platformtechnologies.org) for all biotechnology platforms in the state to maximize the use of shared resources and expertise and to minimize the duplication of costly technology platforms and services across the state. In many other countries, including Canada, initiatives come mainly from groups of researchers who see the need to share resources and, most importantly, highly specialized expertise.

The Canadian Network of Scientific Platforms (CNSP) was created in August 2016 and aims to bring together researchers, scientific platform scientists, and research administrators from across Canada to share experience and find creative ways to fund and sustain high-level scientific infrastructure platforms. A definition of what constitutes a scientific platform and the detailed mandate of the CNSP can be found on the website www.cnsp-rcps.ca. Briefly, the network aims to promote awareness about scientific platform resources available to the research community, educate researchers about advanced technologies, develop best practices for operation and management, create a cooperative culture, and promote interactions with industry leaders to encourage and guide continued development of infrastructure and applications. The network also aims to become the voice of the community to federal and provin- cial funding agencies to ensure the optimal and sustained use of scientific infrastructure investments.

Institutions are recognizing the need for appropriate, clear, and well-defined career paths in order to recruit and retain highly qualified personnel to train, manage, and direct these specialized technology platforms. These positions cannot simply be management or training based, although these aspects are important. Managing scientists should remain engaged in research projects and programs, both to stimulate their scientific curiosity and to keep them involved and current in the technologies that they are supporting. Ideally, core facility scientists should be engaged in grant writing, publishing, experimental design, implementation, and data analysis and interpretation.

Core facilities offer many services for the use of advanced technologies. In a typical consultation between researchers and core facility experts, the experts provide recommendations for the most appropriate core facility technology to address the research question, as well as how to properly prepare samples and collect, analyze, and interpret data. A brief (30-60 min) meeting typically will save researchers weeks of research time, and information and assistance with the development of proper sample preparation techniques can potentially save months of work. The net result is more rapid results and higher-quality data.

Many core facilities - including microscopy, screening facilities, and cell analyzer technologies in flow cytometer cores-typically operate under a model in which users are trained to use equipment independently. Other centralized technologies — such as fluorescence-activated cell sorting (FACS), next-generation sequencing, and mass spectrometry-often operate with a full service model. For user-trained cores, training is typically conducted one-on-one by core facility staff, and the researcher, once sufficiently trained, can use the equipment unsupervised. Typical training sessions focus on key aspects of the technology that are specific to the users' need. Another key role of core facilities is training and education, which provide users with opportunities for a more in-depth under- 
standing of the technologies that they are using in their research. Most facilities offer internal and external educational opportunities in the form of one-on-one training, workshops, tutorials, and courses. Several large-scale intensive microscopy-specific training programs exist across North America and Europe. One way to find out about these opportunities is through notices posted on a highly active international confocal listing service (http://lists.umn.edu/ cgi-bin/wa?A0=confocalmicroscopy). The name implies that the list server is about confocal microscopy, but it really is a tremendous resource for anything related to light microscopy. The list is archived and searchable back to 1991 .

Core facilities must also maintain equipment in a good state of repair and operation, requiring a tremendous amount of time and funding. Service contracts for high-end confocal microscopes, for example, start at $\sim \$ 20,000$ per year/per instrument and can run as high as $\$ 30,000-\$ 40,000$ per year. In addition, it is crucial for facility staff to clean, service, and monitor instrument performance on a regular basis to detect and deal with problems before they begin to affect user data or result in equipment downtime. In my experience, many issues are not obvious with routine use of the equipment and are not apparent to instrument users, but they can have a severe impact on quantitative data analysis and interpretation (Stack et al. 2011).

There is no sign that technological development will slow down or that the complexity of instrumentation will lessen in the foreseeable future. Therefore, core facility job opportunities will continue to grow.

\section{JOBS}

Below, I consider the features and issues of core facilities in general and, in particular, of the microscopy facility, which is my own area of expertise. In fact, the microscopy core facility represents a good model for other facilities.

Core facility positions range from the routine technical to the highly technical to management and scientific oversight. Many entrylevel positions can be seen as wonderful training opportunities and do not necessarily require a Master's or PhD-level degree. I have undergraduate students working in my facility and a few graduate students working part time to gain experience in microscopy. The ideal hierarchy for an efficient, well-run core facility is shown in Figure 1. With the expanding number of core technologies, most major U.S. institutions now have a highly trained scientist and administrator in the lead role. However, many institutions are

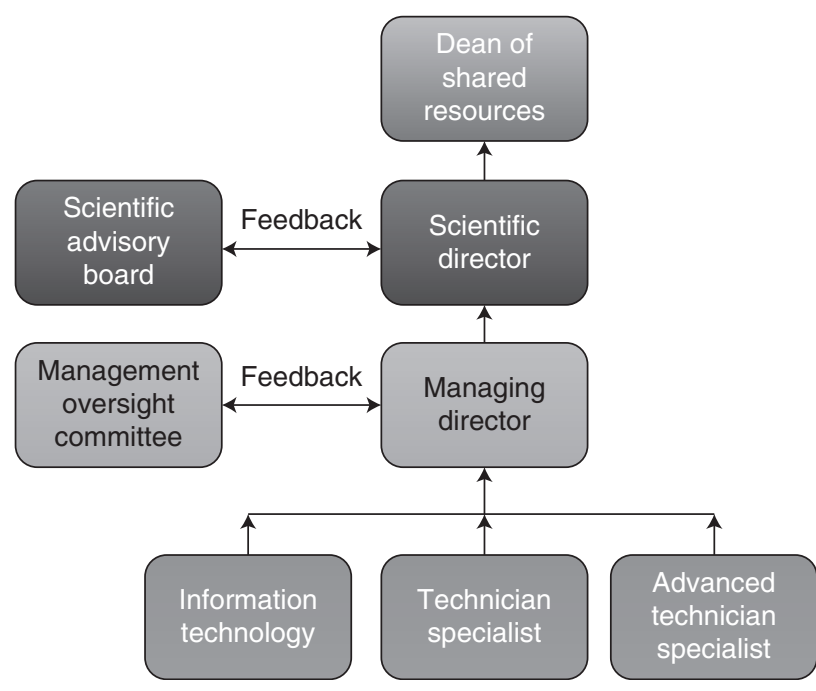

Figure 1. Hierarchy of core facility staff, oversight and administration, and career development paths. 


\section{C.M. Brown}

far from this ideal model, with a single core facility staff member taking on all of the management, training, and technical roles. In these cases, the core facility typically is unable to achieve all of the aspects discussed here but can only focus on the core tasks of training and use of existing technologies.

\section{Entry-Level Positions}

Entry-level positions will vary with the nature of the core facility and its technology but usually fall under the title of technician, responsible either for the general operation of the equipment or information technology support.

\section{Technician Specialist}

The technician specialist assists with the general operation of the core, such as ordering supplies, maintenance and quality control of instruments, and keeping training records up to date. Other responsibilities include basic training on equipment use, data collection, and perhaps data interpretation. Troubleshooting is also expected; that is, addressing questions that users have throughout the day, evaluating and solving problems with equipment, and addressing experimental design issues that arise. Assistance with educational opportunities, such as workshops and courses, is also an important part of this job. This ensures that the specialist stays current on existing and new technologies and learns how to communicate them to facility users.

\section{Information Technology}

Information technology (IT) is often undersupported in academic environments, but its importance for a smooth running core, ready access to research data, and support of file processing and analysis cannot be overstated. Most core facilities could not support a fulltime IT staff member, but access to $25 \%$ of someone's time is a minimum requirement. Four general areas of ITexpertise are required to support the facility. First, overseeing database and networking involves monitoring networking equipment and storing and backing up images, databases for instruments such as sequencing information, chemical libraries, RNAi (RNA interference) libraries, and image databases (e.g., high-content screening microscopes). Second, a large role of any core involves data handling; that is, giving researchers access to their data and the software required to analyze the information that they generate on core facility equipment. In microscopy cores, this includes postimage acquisition data processing, so advanced workstations, image processing software, and image analysis software are required. Third, keeping equipment running smoothly involves keeping computer operating systems (MS Windows/Apple OS) running efficiently, routinely updating software interfaces and component drivers, and assuring that these are virus free. The fourth responsibility is development and maintenance of the facility web pages that provide the interface among facility users, management, and technology platforms. This includes fee information, equipment specifics, papers published with data generated by use of the core, and equipment booking and billing software. Having an effective web page is tightly linked to core facility efficiency, appeal, and communication.

\section{Mid Level \\ Advanced Technician Specialist}

The position of advanced technician specialist is similar to the entry-level technician/microscopy specialist but requires more expertise and knowledge of advanced applications, instrumentation, and troubleshooting issues. For example, training experiences for higher-end microscopy systems could involve training in advanced technologies such as fluorescence photobleaching, live-cell microscopy, fluorescence resonance energy transfer (FRET), and multiphoton microscopy. Assistance in developing and implementing educational opportunities would also be a central role in this position.

\section{Manager or Managing Director}

The manager or managing director of the core oversees all aspects of the day-to-day operations 
of the facility and provides staff within the facility adequate supervision and support in order to fulfill their roles within the facility. Importantly, the manager must keep abreast of advances in technology and, together with the scientific director, makes recommendations to the scientific advisory board (Fig. 1) regarding new equipment purchases. The manager additionally consults and works with researchers to determine the appropriate equipment to address specific research questions and assist and guide researchers to develop and implement their experimental designs. Once data is available, the manager may assist users in analyzing and interpreting the data, preparing information for presentations and publications, and presenting preliminary data for grant applications.

The manager oversees basic and advanced training and develops and modifies standard operating protocols (SOPs) or manuals for training sessions, ensures that high-quality training is offered by all facility staff, and ensures the regular maintenance of equipment. In being responsible for interpreting quality control information and initiating repairs and keeping track of repair histories, managers are the key liaison with instrument service departments and must ensure rapid and efficient service to minimize costly instrument downtime.

The manager must ensure that policies are updated to reflect the changing needs and infrastructure, appropriate access to equipment is available for all facility users, and facility users adhere to facility policies and procedures. Oversight of the facility budget, cost recovery system, and monthly and annual reporting is crucial for identifying equipment that is not being used efficiently or is out of date, and for ensuring efficient operation and budget management of the core over the long term. Identification of and application to internal and external funding sources is essential.

The manager must create and develop educational opportunities that cover both the fundamentals of the core technologies as well as the emerging technologies that are relevant for facility users. This includes the development and implementation of workshops, tutorials, and courses. Finally, the manager must initiate and build on corporate relationships with vendors in the field in order to develop partnerships with companies and to have access to appropriate technologies when purchases are being made. This also allows for alpha and beta testing of new state-of-the-art equipment and software and valuable input into how technologies develop.

\section{Upper Level}

The two primary positions at the upper division level are scientific director of the facility (a highly trained scientist) and associate dean of shared resources (having primarily administrative duties).

\section{Scientific Director}

The scientific director must oversee the core facility operations and the managing director, evaluating reports and working with the manager to ensure efficient operation and oversight of SOPs for training and equipment maintenance and of educational initiatives developed and implemented by the core. The director also is typically engaged in research in the field and should have a vested interest in the maintenance, application, and future development of the technologies. This will ensure that the director has adequate knowledge of the ongoing research and the directions in which the field is likely to move toward in the future. In light of this, the scientific director must keep abreast of technological advances to make informed decisions.

A third responsibility is to interact with the scientific advisory board to ensure that the core resources stay current and relevant and also move toward newer state-of-the-art technologies in a timely manner. In turn, the advisory board must ensure that the goals of the scientific director serve the entire scientific community and not just the research area of the director. This is crucial for oversight of core operations and decisions about future equipment purchases. In light microscopy, as in other fields, new technologies carry a considerable price tag and with the diversity of equipment, buying deci- 
C.M. Brown

sions must be strategic and in line with longterm planning in the core and the institution.

\section{Associate Dean of Shared Resources}

The associate dean of shared resources (core resources; shared instrumentation; scientific platforms) provides institutional support and oversight for multiple core facilities in the institution. As an advocate for core technologies, the dean is involved in long-term planning for the viability of existing cores and the implementation of new core resource platforms. Technologies change and evolve, and constant evaluation of and synergy among institutional goals, overall research aims, and relevance of core technologies is required. Thus, in working with scientific directors, the team makes decisions on overall institutional directions for core facility growth and advancement or-alternativelydetermining when cores are no longer viable and need to be closed.

Finally, the dean is responsible both for oversight of the scientific director and advisory board and of the core facility staff. It is preferable if the core facility staff are under the direction of the dean's office with broad research mandates, rather than department or research units that may have more narrow research needs.

\section{SKILLS AND QUALIFICATIONS}

All core facility positions require certain common sets of skills. Among the most important qualifications are a love of learning, the ability to learn quickly to keep up with new technologies, and a passion and determination for solving problems. Time management and the ability to adjust to changing priorities are essential. The nature of facilities is that there are many instruments and users, so being able to troubleshoot equipment problems, act in a service/customer-support-type manner, and react to changing tasks and priorities throughout the day is crucial. Without the ability to multitask and reassess priorities, the core facility is not the place for you. Personnel must use linear, logical reasoning to get at the root of issues and quickly come up with solutions. Hundreds of people use core facilities; thus, an ability to work with individuals with very different personalities, from shy and mild mannered to curt and abrupt, is required. Being personable with a customer support attitude is essential for working with different staff members and facilities users on diverse projects in a service-based environment.

\section{Entry-Level Positions}

The technician or IT specialist typically has a BSc or Master's degree, although in my facility we do have some undergraduate students working in this capacity.

\section{Technician Specialist}

A facility technician should come with experience with core facility technologies and software and be open to additional on-the-job training for highly specific equipment. Some expertise in a specific area may be desirable, for example, in microscopy fluorescent probes, live-cell or organism imaging, or photobleaching and photoactivation. Some technicians may be specifically trained for equipment maintenance and quality control. Being well organized and paying attention to detail are essential for tracking, modifying, and developing effective and efficient SOPs and facility records. Another important aspect of the job is the ability to learn quickly, perform literature reviews, and prepare PowerPoint presentations for teaching basic microscopy principles. Particularly ambitious individuals will have the potential for developing, and even teaching, workshops, tutorials, and courses.

\section{Information Technology}

In addition to the skills described in the introduction to this section, the ideal IT person should have expertise with database, networking, image processing and analysis, data handling, MS Windows and other workstation operating systems, computer equipment interfaces 
and communication, web design, and maintenance.

\section{Mid-Level Positions}

These positions (advanced technician specialist and managing director) are typically held by a $\mathrm{PhD}$-level scientist. However, an ambitious person with a BSc or Master's-level degree combined with some experience as an entry-level microscopy specialist could be appropriate. The positions require those who can both serve as a leader and work as part of a team. They should be interested in learning new technologies and applications, and have excellent communication skills to present complex ideas and explain the technology at tutorials, courses, meetings, and workshops and to other upperlevel administrators in the institution.

\section{Advanced Technician Specialist}

The technical specialist should have extensive experience with both diverse technology platforms and advanced technologies in the field (e.g., for microscopy: FRET, fluorescence lifetime imaging microscopy [FLIM], live-cell or intravital imaging, image correlation spectroscopy [ICM], nanoscopy, and advanced image processing). When advising users of the facility, the specialist should be able to communicate and interact with researchers on advanced projects, have a role in experimental design and implementation, and advise on or assist with grant and manuscript writing.

\section{Managing Director}

The director is expected to have superior management skills and the ability to supervise core facility personnel and coordinate a diverse set of obligations on a daily basis with rapidly changing demands and priorities. Financial management experience is also an asset for preparing budgets and budget reports and delivering these to the management oversight committee.

Networking skills are highly desirable to facilitate interaction with facility users, principal investigators, and potential new clients within the research community. Here too, the ability to develop and maintain strong ties with corporations, including their research and development arms, is an advantage both to influence technology development and to engage in research and development of advanced technologies with commercial companies. Finally, the director must have a longterm vision for maintenance, growth, and development of the core and enhance the flow of information among the management oversight committee, scientific director, and scientific advisory board.

\section{Upper-Level Positions}

The positions of scientific director and dean of shared resources both require a $\mathrm{PhD}$-level scientist with expertise in the field. In addition to the skills described in the preceding sections, these positions involve having and promoting a long-term vision of the available technologies, the development of the core facility, and the ability to maintain synergy with technological developments.

\section{Scientific Director}

The director must be a strong leader with good communication skills to integrate ideas from the scientific advisory board at the level of the core facility operations and to impress upon the associate dean of shared resources the importance of the core activities and long-term direction.

\section{Dean of Shared Resources}

The dean must have a big-picture vision-both short and long term-of how the activities of the facility fit into the overall research goals and mission of the institution, how to phase out technologies (sometimes entire cores), and the ability to continue to develop existing cores and identify and embrace new technologies. Clearly, significant management experience is an asset, as is interest in and familiarity with a wide array of technologies and their applications to problems across multidisciplinary fields. 


\section{GETTING A FOOT IN THE DOOR}

During your studies, make sure to take any and all opportunities to learn the intricate details of the technologies that you use in your research work. With increasing expertise in many technologies, you will find that you will have more opportunities in core laboratories. Take technical and theory-based courses to gain an understanding of the fundamentals behind technologies of interest. Take advantage of opportunities at scientific meetings to network with vendors and find out about existing and new state-ofthe-art technologies. Ask lots of questions and determine what the difficult areas are and what kinds of solutions could move the technologies forward. Sales and technical specialists from corporations are wonderful resources.

Volunteer to help out in core facilities at your institution. Perhaps if you help organize a workshop, you can attend the sessions free of charge. You will likely have networking opportunities to meet core facility staff and company representatives in the process. Consider becoming a superuser on some of the equipment and then help with training on a part-time basis.

Find core facilities in your area using the Association of Biomolecular Resource Facilities (ABRF) Core Facility Marketplace (http:// www.abrf.org/index.cfm/page/resources/ABRF_ Core_Marketplace.htm). When given the opportunity, take advantage of workshops offered in the field. Do not be shy about asking your supervisor; maybe you can attend a scientific meeting or perhaps you can use your budget to attend an intensive course instead. Consider the following opportunities and course listings.

- Cold Spring Harbor Laboratory courses (http:// meetings.cshl.edu/courses.html)

- Molecular Biology Labs in Woods Hole (http:// hermes.mbl.edu/education/index.html)

- Montreal Light Microscopy Course: Fundamentals and Frontiers (www.mlmc.ca) at McGill University (held biannually)

Perhaps you can find similar associations in your area. If you are truly interested in core facility work, definitely attend the annual meet- ing of ABRF, an international association that is rooted in protein- and genetics-based core technologies but is rapidly expanding to include light microscopy as well as many other fields. This annual meeting puts together a wonderful scientific program combined with a focus on workshops, tutorials, and round table discussions, including those regarding core technologies, core facility management, and administration. Check out their website-a resource for all things "core facility" (www.abrf.org). The ABRF regional chapters also hold smaller local meetings across the United States (abrf.org/meetings). The Canadian Network of Scientific Platforms (CNSP) will be holding annual meetings after a successful inaugural meeting in May 2017 (www.cnsp-rcps.ca).

\section{CAREER PROGRESSION}

As core facilities are becoming more common, many universities have well-established centralized oversight and clear paths for career progression. Two examples are the University of Virginia under the leadership of Dr. Jay Fox (https:// med.virginia.edu/core-facilities/) and Northwestern University under the direction of Dr. Philip Hockberger (https://www.facilities .research.northwestern.edu/). Northwestern developed a video about the importance of core facilities including state-of-the-art technology and highly qualified scientists. It summarizes the importance of cores in less than 5 minutes (https://www.youtube.com/watch?v=oXtKpJ3 Va9w).

In general, from an entry-level position, MSc- or PhD-level scientists could expect to be considered for manager/managing director-type positions after at least five years of experience in their graduate/postdoctoral studies or as a microscopy specialist or similar position. Initiative to take on additional responsibility, keeping up on technology developments and advances, and the ability to work well with facility users and colleagues will all go a long way in getting a promotion. Core facility management positions are limited and positions tend to be highly specialized, so be prepared to relocate in order to move up to a 
management position unless you are within a large institution or large urban center with many research institutions. Promotions from a position such as a technician specialist to an advanced technician specialist are more likely to occur internally within a single core facility.

Depending on the background and experience of a core facility manager, there may be opportunities to move from this position to that of a core facility scientific director or associate dean of core resources. To move into a position of scientific director would require having a $\mathrm{PhD}$ and an independent research program. If you were not initially hired to start up an independent research program, this could still be achieved through collaborative efforts within the core facility. After 5-10 years of experience and the development of independent research projects, it would be possible (although not common) to be promoted to scientific director. More typical is the scenario in which a scientific director is an established independent investigator at the institution or a midlevel career scientist recruited to the institution for this position. Movement from core facility management to associate dean of core resources would be a more typical career path. Figure 1 shows the hierarchy of reporting, but a manager could move directly into a core facility administrator position without becoming a scientific director. This is a logical transition, if strong management skills are developed and the manager has a clear understanding of multiple core technologies and how they are applied to research questions. This kind of promotion would be considered only for PhD-level scientists after at least 10 years of experience as a core manager. In this case also, these positions are limited and relocation may be necessary.

\section{WAY OUT}

Training that is obtained in a core facility is highly applicable to many other job sectors. Lateral moves into corporate positions and biotechnology and pharmaceutical companies are possible, because core facility staff have tremendous expertise in technologies with broad applications.
Lateral moves into sales positions at companies selling instrumentation in the field or reagents/consumables associated with the technology are possible at many stages during a core facility career. It is not advisable to consider this type of move until you have at least a couple of years' experience with the technology. Sales positions require detailed knowledge of the products and how they are used, and it is logical for core facility staff to have this kind of expertise. When making a lateral move to a company, make sure that you do your research first. Know the company and their products. This makes a transition into a sales or technical specialist position much easier. An appreciation for the breadth of applications of the technology is also important. In turn, the potential customers are likely already familiar and the same core facility network can be used as an initial sales base. Be aware, however, that the work environment and goals in the corporate world are very different from the academic environment; therefore, be prepared for sales quotas and hard and fast deadlines.

Technical specialist positions within companies are ideal lateral moves for core facility staff with their tremendous expertise and training. These moves should be made only after threefour years in a core facility when appropriate expertise has been developed. One-on-one training in a core facility is very similar to oneon-one scientific support from a company specialist. The customer-based focus also translates well to a corporate environment. Extensive experience with technology, pitfalls, and troubleshooting is an asset. Technical specialists also spend a lot of their time educating existing or potential customers. Experience with workshops, tutorials, and courses in the core facility will develop these same skills for use as a technical specialist.

Lateral moves can also be made into biotechnology or pharmaceutical companies that use the same technologies as the core facility. Many companies are now running core facilities with shared instrumentation in a very similar way to academic institutions. Again, do your research, know the companies, and sell yourself based on your expertise and training. 
C.M. Brown

\section{BOX 1. My Experience}

I never set out on a career track for core facility management. However, in looking back, I see it is a position that perfectly suits my interests, expertise, and personality traits. My scientific interests are diverse, and I love to learn new things, network, and work with people. I like to multitask and enjoy teaching, and I have the privilege of going to work each day to a job that I truly enjoy.

My formal training is in physical chemistry; however, I have always liked the interface among the scientific disciplines where routine knowledge in one field can revolutionize another. At the interface among chemistry, physics, and cell biology, I have developed my specific expertise in applying biophysical tools to problems in cell biology. While working in physics, chemistry, and cell biology laboratories, I have picked up tricks of the trade and developed a real sense of how these three communities of scientists operate and what scientific questions that they find important. Because I like working with people and helping them reach their goals, in graduate school I became involved in many projects with other graduate students and postdocs. During my first postdoctoral fellowship position at the Curie Institute in Paris, I worked with a group of physicists on a home-built multiphoton microscope (pretty rare in 1998), applying it to a beautifully developed system of intestinal cells expressing brush border myosin I green fluorescent protein (GFP). The cell biologists prepared all of the mutants and controls, with the GFP-fusion protein placed under an inducible promoter to avoid cellular compensation for overexpression of the protein, and I found myself looking at the dynamics of myosin in live cells.

I moved back to Canada for the birth of my son in 2000, unsure of what was coming next. During a 10-month teaching position in the chemistry department at Mount Allison University in New Brunswick, I discovered that I loved teaching. (I also had a newfound appreciation for all of my former teachers; it is a lot of work!) Nevertheless, I felt the novelty and excitement of primary research calling me back. After a brief and disappointing postdoctoral position in a dysfunctional laboratory (an experience that helped me with my "dos and don'ts" list below), I joined the first-rate laboratory of Rick Horwitz at the University of Virginia. That laboratory was very multidisciplinary, and I learned many more intricacies of live-cell microscopy. Quickly becoming the go-to person for any technical aspects of the microscopes, I learned a great deal more about cell biology, signaling, migration, and, of course, about microscopes. Then, taking the position of the core facility manager at McGill enabled me to move back to Canada, work on many research projects, and fulfill my broad research interests.

Now, I work on projects ranging from materials science to live organisms. I contribute to hundreds of other projects and collaborate with many students and postdoctoral fellows. I also enjoy working with companies and having a role in technology development. Networking, engaging the sales representatives and technical specialists, and working to improve the instrumentation, software, and reagents on the market enables me to help the community to better address novel scientific questions. The constantly evolving nature of the field of microscopy satisfies my love for continually learning new things. I quickly identified education as the key to a successful core facility. As a result, during my 12 years at McGill, I have run more than 80 workshops, tutorials, and courses. The technology is available; we just need to ensure that we use it well to perform high-quality science for scientific advancements and reputable publications. In 2011, I was appointed assistant professor, and I was promoted to associate professor in 2016. I now have an active research lab applying advanced biophysical tools to the study of the fundamentals of cellular migration and cell migration in breast cancer. My lab also works on engineering incident light for fluorescence live imaging to optimize conditions and minimize phototoxicity. Although this situation is challenging for time management, it is also mutually beneficial. My lab has access to a world-class facility and we develop technologies that can be rapidly implemented in the core. In 2016, I also took over the management of two other microscopy core facilities at McGill, so access to light-microscopy resources is now streamlined for all members of the life sciences complex research community. I never set out to work in a core facility, but it perfectly suits my personality, my interests, and all that I love about science. 


\section{BOX 2. Ten Dos and Don'ts}

1. Do make phone calls and send mail. In this information age, people often receive hundreds of e-mail messages a day. Stand out by calling or sending a hard copy of your CV by oldfashioned snail mail. Join online professional sites such as Linkedln (http://www.linkedin .com). In addition, join and watch discipline-specific listing services such as the confocal list.

2. Do get everything in writing. When interviewing for jobs, many promises are often made; make sure there are specific milestones and dates in order to ensure that the promises do not become forgotten and unfulfilled.

3. Do talk to people at many levels on a one-on-one basis so that they have an opportunity to be candid with you about the work environment and whether it is healthy.

4. Do find out in advance what type of career track the institution is offering for core resource facility staff. Determine exactly the type of funding model used for the core.

5. Do choose a career doing what you love. Nothing makes you more productive than looking forward to going to work each day.

6. Do not get too friendly with prospective employers. It comes across as being unprofessional.

7. Do not overprepare. I once got a binder full of every certificate and letter a potential candidate ever received in their career. You need to do the work to highlight a few key achievements in your interview, so as not to overwhelm.

8. Do not expect to get long-term stable employment contracts with core facilities (at least not in the current climate). You may luck out, but most are completely or partially funded on soft money, and institutional support is on the decline (Riley 2011).

9. Do not get discouraged. At a talk I attended, the speaker showed his rejection letter from a prominent journal saying his future Nobel Prize-winning work was not novel or relevant to the readership of the journal.

10. Do not undervalue other options for a scientific career. Some people feel the ultimate goal of any scientist should be to start their own independent research program. This is not for everyone and there is equal value in many other careers. Go where you will use your gifts and talents to their full potential and where you will be happy.

Lateral moves into academic positions to set up an independent research program can be difficult even for a core facility manager. If research is not a major component of the core facility position from the beginning, this door may be closed. Most academics hiring into research positions want researchers to follow the traditional career track of graduate work, postdoctoral work, and then a faculty position. Although not impossible, this is not typical. Therefore, before moving into a core facility job, be sure that you do not want to run your own independent research program unless it is part of the position or long-term plan from the beginning.
Finally, creating a business with core facility tools and talents is possible. Offering expertise for research projects and grant applications, training scientists to use equipment in their laboratories, maintaining equipment, and training in data analysis and presentation for publication can all be done within the framework of a consulting service for researchers at multiple institutions. All of the benefits of having your own business, making your own schedule, working at your own pace, and making decisions will follow. Be sure, however, that there is sufficient market for your expertise in your area before taking the plunge. 
C.M. Brown

\section{REFERENCES}

Riley MB. 2011. University multi-user facility survey: 2010. J Biomol Tech 22: 131-135.

Stack RF, Bayles CJ, Girard AM, Martin K, Opansky C, Schulz K, Cole RW. 2011. Quality assurance testing for modern optical imaging systems. Microsc Microanal 17: 598-606.

\section{WWW RESOURCES}

www.abrf.org The Association of Biomolecular Resource Facilities (ABRF), an international society dedicated to advancing core and research biotechnology laboratories through research, communication, and education.

http://www.bio21.com.au/projects/view/1 The Bio21 Cluster-Victoria's leading health and medical cluster.

www.cnsp-rcps.ca The Canadian Network of Scientific Platforms (CNSP). www.cytometry.ca Canadian Cytometry \& Microscopy Association, Montreal, Quebec.

http://hermes.mbl.edu/education/index.html The Marine Biological Laboratory (MBL) education programs, Woods Hole, Massachusetts.

http://www.linkedin.com LinkedIn, the professional network homepage.

http://lists.umn.edu/cgi-bin/wa?A0=confocalmicroscopy Confocal Microscopy, University of Minnesota.

https://med.virginia.edu/core-facilities/ University of Virginia core facilities.

http://meetings.cshl.edu/courses.html Cold Spring Harbor Laboratory Meetings \& Courses Program.

www.mlmc.ca Montreal Light Microscopy Course (MLMC).

https://www.facilities.research.northwestern.edu/ Northwestern University core facilities. 


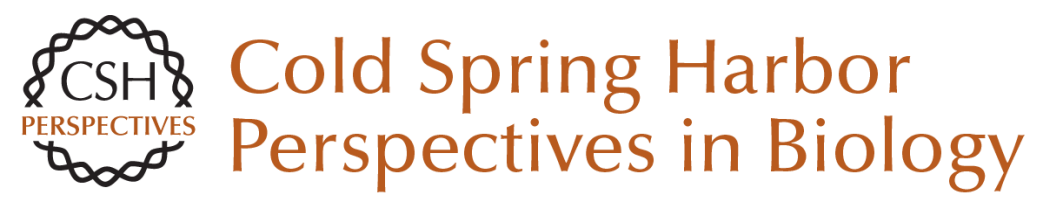

\section{Careers in Core Facility Management}

Claire M. Brown

Cold Spring Harb Perspect Biol 2018; doi: 10.1101/cshperspect.a032805

\section{Subject Collection Career Options for Biomedical Scientists}

\section{Careers in Science Publishing} John R. Inglis

Medical Communications: The "Write" Career

Path for You? Yfke Hager

At the Crossroads of Science and Society: Careers in Science Policy Amy P. Patterson, Mary E. Groesch, Allan C. Shipp, et al.

A Career in Patent Law: At the Cutting Edge of Science, but Not at the Bench Salim Mamajiwalla

Careers in Science and Grant Administration: View from the National Institutes of Health Marion Zatz and Sherry Dupere

Careers at Biotech Start-Ups and in

Entrepreneurship Susan Froshauer

Careers in Science Journalism and Writing Helen Pearson

\author{
Careers in Academic Administration \\ Lydia Villa-Komaroff \\ Working for a Scientific Society \\ Martin Frank
A Career for Life Scientists in Management Consulting Rodney W. Zemmel \\ Careers in Core Facility Management \\ Claire M. Brown \\ Leaving the Bench and Finding Your Foundation \\ John E. Spiro
A Career at a Small Liberal Arts College Jennifer Punt \\ Career Options for Scientists \\ Richard Sever and Kaaren Janssen
}

For additional articles in this collection, see http://cshperspectives.cshlp.org/cgi/collection/

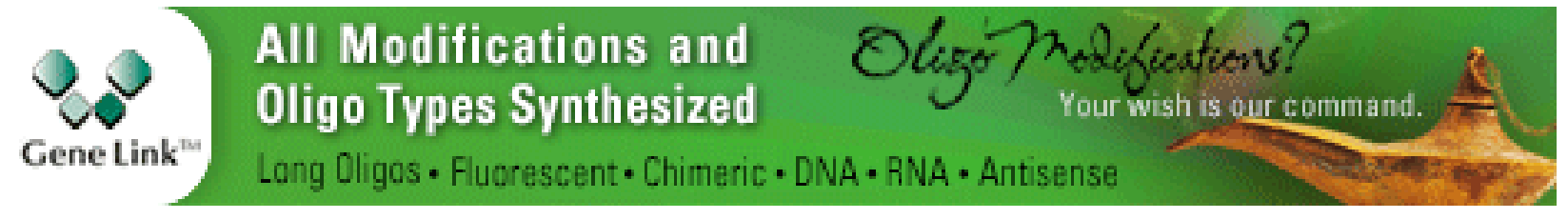

